\title{
Evaluation of sintered gears in operational conditions
}

\author{
Mariusz Rosiak $^{1, *}$, Jerzy Napiórkowski ${ }^{2}$, Magdalena Lemecha ${ }^{2}$ \\ ${ }^{1}$ Opole University of Technology, Poland \\ ${ }^{2}$ University of Warmia and Mazury, Poland
}

\begin{abstract}
This article presents the description of tested gears that were made from sintered material, as well as of gears made of grade $16 \mathrm{MnCr} 5$ steel (number 1.7131), which are installed in transmissions of power tools. The procedure for the gear tests was described, and a test bench and the methodology for carrying out the tests were presented. The aim of the article was to examine whether sintered gears could replace gears made of steel $16 \mathrm{MnCr} 5$ while maintaining the required stability in operating conditions. The results of the evaluation of geometry changes and the results of metallographic examinations were presented. The results achieved were analyzed and the sintered gear technology was evaluated. Recommendations were formulated concerning the enhancement of the technology with which sintered gears are produced in order to obtain products with even higher operational properties.
\end{abstract}

\section{Introduction}

Sintered products made from metal powders are winning even greater recognition from machine manufacturers. The automotive industry, among others, is showing its exceptionally high interest in the technology. A possibility to manufacture cheap parts that can work under high and complex loads, manufacturing without waste, reduction or elimination of machining in the technological process, no fibrousness of a material, lower mass, adjustable density size and distribution constitute only a part of the characteristics which render manufacturers highly interested in sintered products made from metal powders. It is very popular to manufacture small sintered parts in mass production, such as pistons, rings, plain bearing sleeves, gears in transmissions [1], while the automotive industry is the industry that is introducing sintered elements in their products at the highest pace [2]. The global market for powder metallurgy (PM) parts is expected to reach US\$ 15.7 billion by 2020 , driven by emerging applications in transport, construction and engineering. It is also expected to benefit from the recovery of the global automotive industry and an optimistic outlook for the commercial aerospace market growth. It is important to try to test the stability of sintered components in operating conditions. In order to prevent and limit possible damage to them in operating conditions, such parts are subjected to various tests in order to evaluate their stability [3]. Machines as entire technical systems are also subjected to the stability evaluation

\footnotetext{
*Corresponding author: m.rosiak@po.opole.pl
} 
tests. Nowadays, modern methods for testing the mechanical condition of machines, such as thermal analysis, vibration analysis or acoustic effect analysis, are available. Some of these methods are characterized by high effectiveness; however, the results of such stability tests have a significant risk of uncertainty. Such a state of affairs gives an incentive to devise more effective methods for evaluating damage [4] and to approach individually the evaluation of operational stability of parts with physical modelling methods, which reproduce the actual operating conditions as closely as possible.

\section{Test methods}

The aim of the test was to examine the operating stability of sintered gears in conditions similar to operating and to evaluate the feasibility of their application as an alternative to steel $16 \mathrm{MnCr} 5$ (1.7131) gears that have been used in transmissions of power tools so far. Sintered gears were made from DISTALOY AE metal powder, which was selected based on the following criteria: predisposition of metal powder to produce parts with high strength properties, good compatibility, and chemical composition that provides high strength properties of a part after heat treatment, availability on the market and economic relationships. In order to enhance strength properties of a heat-treated part, DISTALOY AE metal powder was enriched with $0.3 \%$ carbon by adding graphite during a charge preparation phase. The sintered gears were made in typical conditions of powder metallurgy for this kind of material, which involved the following operations: preparation of a powder charge, compaction, sintering, and calibration. The chemical composition of DISTALOY AE metal powder is shown in Table 1[5]. The geometry of the tested gears is shown in figure 1.

Table 1. Chemical composition of the powder used to make sinters.

\begin{tabular}{|c|c|c|c|}
\hline \multicolumn{4}{|c|}{ DISTALOY AE } \\
\hline \multirow{2}{*}{ Element } & \multicolumn{3}{|c|}{ Element content \% } \\
\cline { 2 - 4 } & Min. & Max. & Actual \\
\hline $\mathrm{H} 2$ loss & - & 0.15 & 0.09 \\
\hline $\mathrm{C}$ & - & 0.01 & 0.01 \\
\hline $\mathrm{Ni}$ & 3.60 & 4.40 & 3.98 \\
\hline $\mathrm{Cu}$ & 1.35 & 1.65 & 1.50 \\
\hline $\mathrm{Mo}$ & 0.45 & 0.55 & 0.50 \\
\hline $\mathrm{Fe}$ & & & Rest* $^{*}$ \\
\hline
\end{tabular}

Rest* - ASC 100.29 powder, which is the basis for the production of DISTALOY-type metal powders.

Performance tests of the test gears were carried out on a test bench, which was built for this purpose and aimed at obtaining the actual operational conditions of drills [6]. The tested gears were installed in transmissions of electric drills. The selected gear made of steel $16 \mathrm{MnCr} 5$ (1.7131) and the sintered gear for tests are shown in figure 2. The diagram of the test bench is shown in figure 3 .

Total operating time of each gear was 800 hours. The gears installed in transmissions of drills operated in a cyclical manner at a rated voltage of $230 \mathrm{~V}(\mathrm{U}=230 \mathrm{~V})[6]$. 


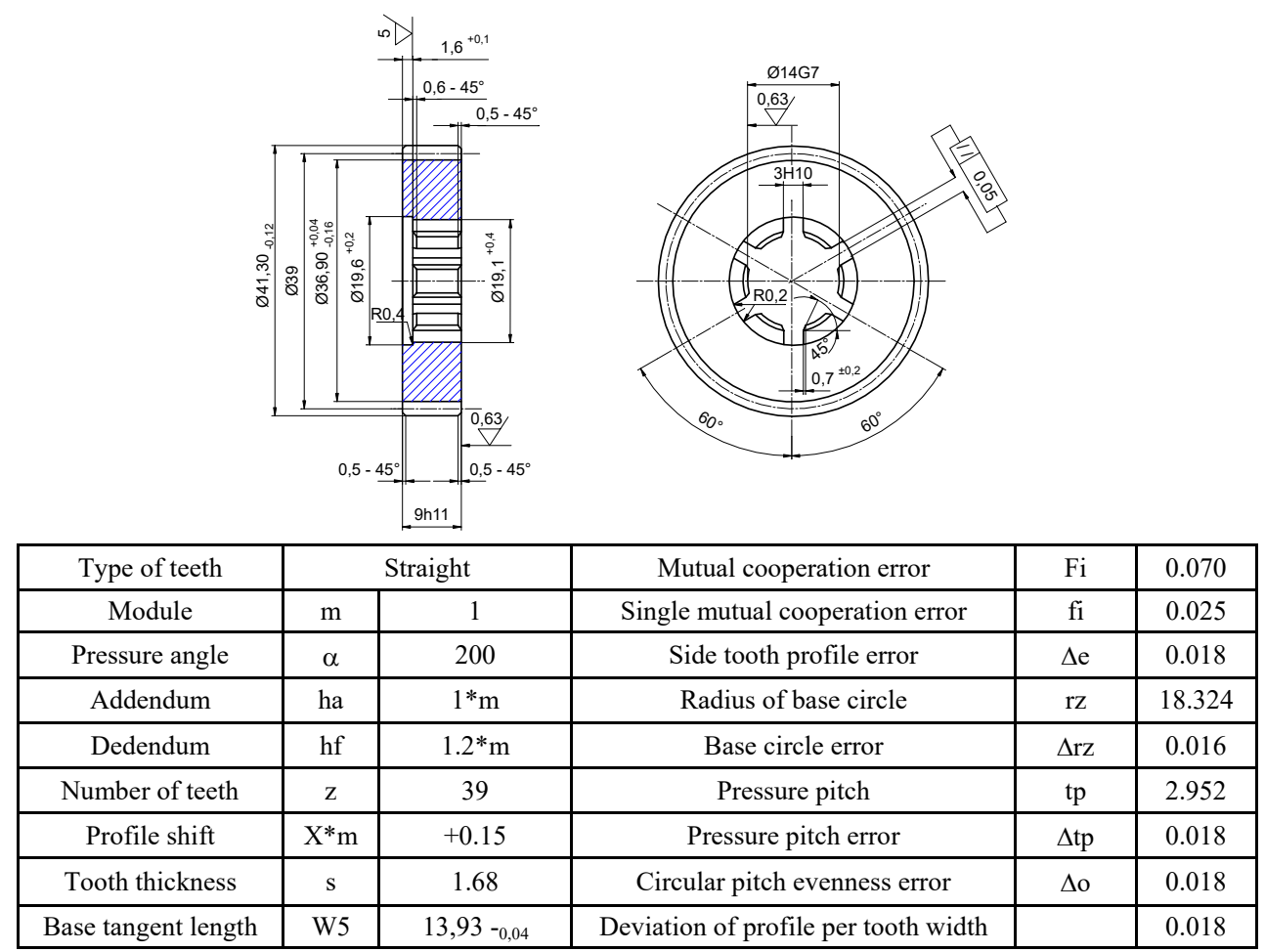

Fig. 1. Drawing of gears used in tests.

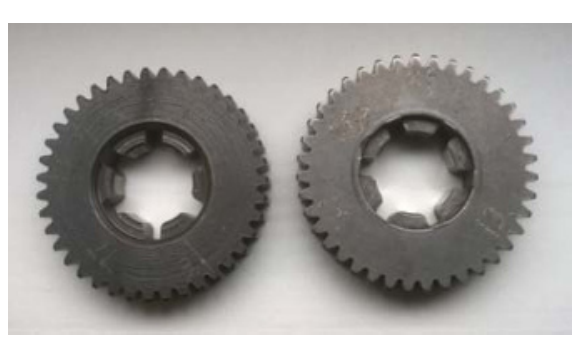

Fig. 2. The selected gears for operational tests on the test bench: steel $16 \mathrm{MnCr} 5$ (1.7131) gear on the left, sintered gear made from DISTALOY AE $+0.3 \% \mathrm{C}$ metal powder on the right.

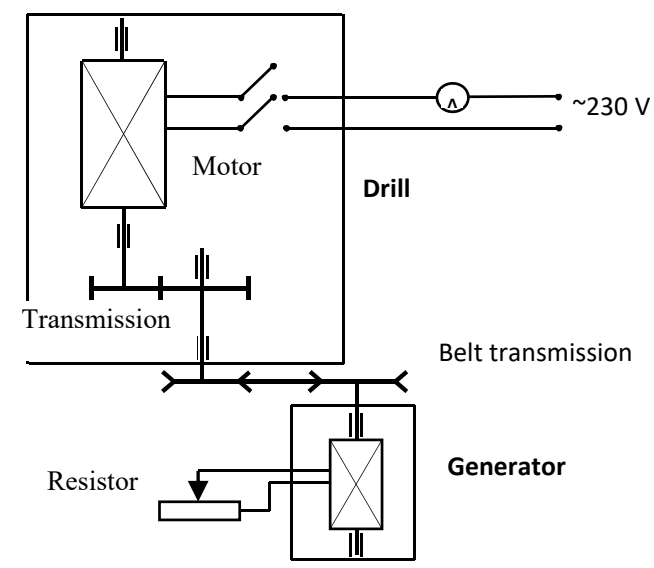

Fig. 3. Diagram of the test bench for gear tests.

Drill tests on the test bench were performed according to the following plan: 2-hour working cycles (involving the following phases: drill work time under load for $100 \mathrm{~s}$, then a 20-s break), and 1-hour breaks for the drill to cool off. The repeated 2-hour working cycles followed by 1 -hour breaks were carried out over the next 50 hours. Then, the drill in the grip was rotated 900 [6], and the tests according to the above plan were resumed. The work time included 20-s breaks but it did not include 1-hour breaks for the drill to cool off. Before the tests began, the gears were subjected to geometry measurements and a general assessment. The geometry measurements included dedendum diameter, addendum diameter, whole diameter, groove width, base tangent length W5, single cooperation error fi, total cooperation 
error Fi (see figure 1). After each 200 hours of operation (i.e. after 200 h, 400 h, 600 h, 800 $\mathrm{h}$ ), the drills were disassembled, the gears inside removed and washed in paraffin. Then, the gears were subjected to measurements, which at the same time involved checking whether they were damaged with the naked eye.

\section{Test results}

The values of the selected geometry parameters of the gears after the testing periods on the test bench are shown in Figure 4-5. Importantly, in the process of gear wear, there are changes of the condition of the surface and dimensions where the cooperating parts, which bear the load, have a direct contact with each other. The toothed-wheel rim and spline grooves were especially exposed to the change of the surface and geometry. The evaluation of geometry changes of the toothed-wheel rim was made on the basis of the results of the base tangent length W5 measurements through five teeth.

The sintered gears underwent metallographic examinations. Structure photographs were taken in the cross section of the tooth in zooms from 50 to 500 times. After heat treatment (austenitization combined with quenching in oil) of the gear, metallographic examinations of the structure of the gear material, which was made from the sinter based on Distaloy AE powder, revealed that it had a very complex structure. Inhomogeneity of the chemical composition and the presence of pores (voids) contributed to a diverse process of heat transfer phenomenon in local areas. Across the entire section, evenly distributed areas of coarse acicular martensite, surrounded by fine acicular martensite, which transform into bainine, were revealed. In the structure, there was a very small number of white ferrite grains surrounded by narrow areas of fine pearlite and bainine. Areas with coarse acicular martensite reach a maximum hardness of approx. $1000 \div 1050$ HV0.1.

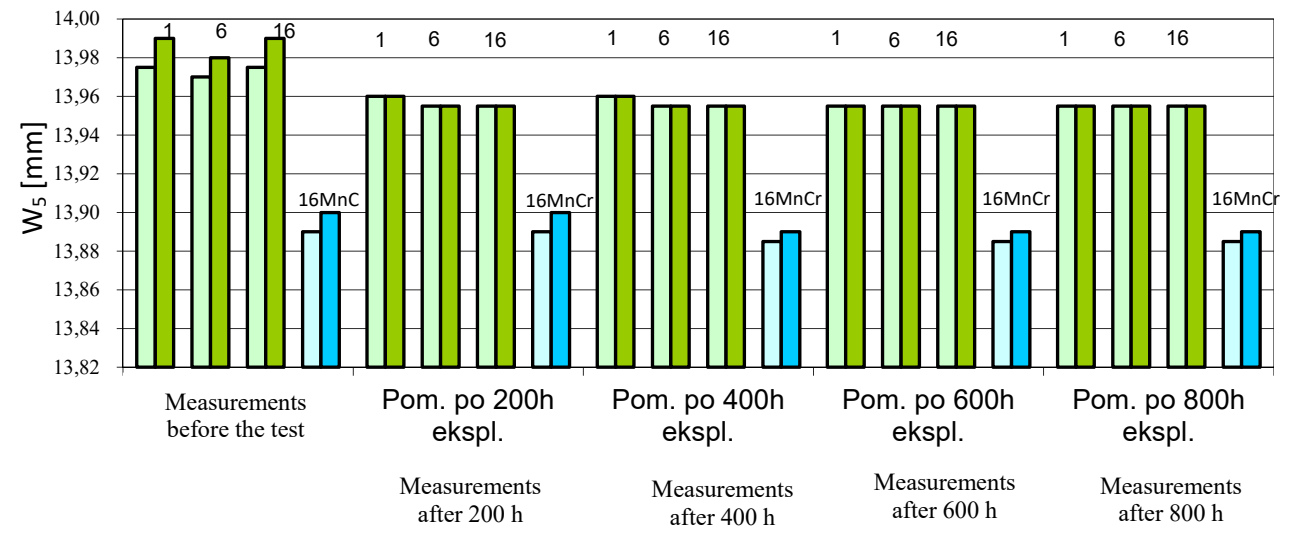

Fig. 4. Values of a base tangent length measurement W5 [mm] (Figure 2) "base tangent length through 5 teeth", measured in sintered gears and steel $16 \mathrm{MnCr} 5$ (16HG) gears after operational periods $(1,6,16$ - marks of the tested gears made from Distaloy $\mathrm{AE}+0.3 \% \mathrm{C}$ powder, $\square \square$ minimum value, $\square \square$ maximum value, allowed difference between maximum and minimum length W5 is 0.04 $\mathrm{mm})$.

The evaluation of the geometry change of spline grooves was made on the basis of the measurements results of the spline groove width (Fig. 5). 


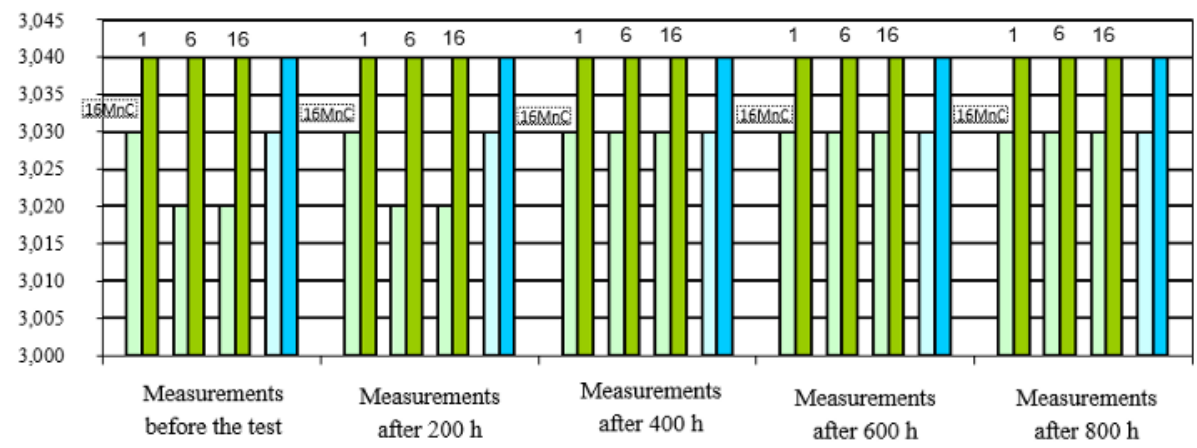

Fig. 5. Values of a "spline groove width" measurement $\mathrm{L}[\mathrm{mm}]$ measured in sintered gears and steel $16 \mathrm{MnCr} 5(16 \mathrm{HG})$ gears after the operational periods $(1,6,16$ - marks of the tested sintered gears, $\square \square$ minimum value, $\square \square$ maximum values, 3 H10 size and tolerance zone of the spline groove width).

The presence of alloying components and $0.3 \% \mathrm{C}$, which involved adding graphite (during the charge powder preparation phase) to Distaloy AE powder, enabled the gear material to obtain so high hardness after austenitization and quenching in oil. Metallographic images of the structure from the area of the sintered gear tooth are shown in figure 6 .

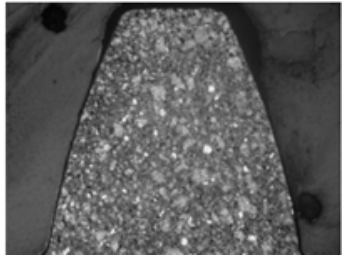

a. $\mathrm{x} 50$ zoom

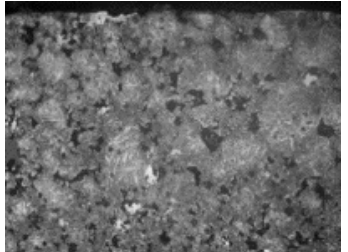

b. $\mathrm{x} 200$ zoom

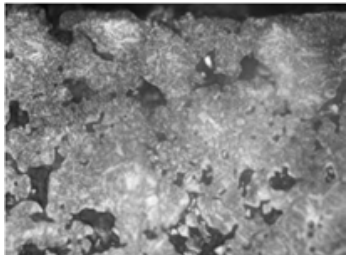

c. $x 500$ zoom

Fig. 6. Images of the structure taken on the cross section of the sintered gear tooth (material -Distaloy $\mathrm{AE}+0.3 \% \mathrm{C}$, heat treatment - austenitization and quenching in oil).

\section{Discussion of the results}

The measured mean value of length W5 (base tangent length through 5 teeth) on the gears made from powdered material before the tests using the test bench was $0.05 \mathrm{~mm}$ higher than the basic length. After $200 \mathrm{~h}$ of operation, there was a significant change in the value of length W5. Further hours of operation of the gear did not have a significant impact on the value of the base tangent length. The maximum change of length W5, which was measured after 800 hours of operation, was $0.035 \mathrm{~mm}$, so it was lower than the minimum tolerance of $0.04 \mathrm{~mm}$. The mean value of base tangent length $\mathrm{W} 5$, which was measured on the steel $16 \mathrm{MnCr} 5$ gears before the tests, was $13.89 \mathrm{~mm}$. After 400 hours of operation, the value changed noticeably to $13.887 \mathrm{~mm}$. Further operation of the steel $16 \mathrm{MnCr} 5$ gears on the test bench until the end of test, i.e. until 800 hours passed, did not have an effect on the change of the base tangent length value. The gears based on metal powders showed no difference between the minimum and maximum values of the base tangent length after first 200 hours of operation and further operation hours. The steel $16 \mathrm{MnCr} 5$ gears showed small differences between the minimum and maximum values of the base tangent length after each operational period.

The spline is the other essential element in the gear structure, which is directly involved in bearing loads. The width of spline grooves in the gears based on metal powders before the 
operational tests showed higher differences than the steel $16 \mathrm{MnCr} 5$ gears (see figure 4). After 400 hours of operation on the test bench, both gears based on metal powders and steel $16 \mathrm{MnCr} 5$ gears were characterized by a small difference between the measured values of the spline groove width, which did not exceed the tolerance zone. The analysis of the results achieved indicated high dimensional stability of the tested gears. Examinations of the surface condition of the tested gears with the naked eye after the operational periods did not reveal any changes. No cracks, cavities or damage were noticed. The measurements of the tested gears in respective operational periods, as well as after 800 hours of operation, showed that the geometry dimensions of the gears changed to a smaller extent than the allowed dimensional tolerance (the stability of solid steel gears is assured for 400 hours of operation).

Due to the dimensional stability, the tested gears could have been further used. The performed tests enabled the formulation of the following statements:

- the results of the geometry measurements of the tested gears after consecutive operational phases showed no changes of the geometry that exceeded the dimensional tolerances;

- this new technology can be used to manufacture gears for transmissions of power tools due to high dimensional stability;

- no damage to the surface of the tested gears was observed, even after their normative operation time was increased by another 400 hours;

- the applied technology of manufacturing gears, based on iron powder as charge material, enabled the products that meet the stability requirements to be obtained;

- the presence of porosity in the sintered material of the gears did not initiate the development of micro cracks in the structure, which could have led to premature damage and the separation of material particles from the surface.

\section{References:}

1. http://www.inop.poznan.pl/

2. http://www.strategyr.com/MarketResearch/Powder_Metallurgy_Market_Trends.asp

3. J. Krolczyk, G. Krolczyk, S. Legutko, J. Napiorkowski, S. Hloch, J. Foltys, E.Tama, Tehnicki Vjesnik - Technical Gazette, 22 (6), 1447 - 1456 (2015)

4. R. Kumar, S. Chattopadhyaya, S. Hloch, G. Krolczyk, S. Legutko, Maintenance and Reliability, 18 (1), 128 - 135 (2016)

5. www.hoganas.com

6. PN-85/E-08400/02, PN-92/E08409, 